\title{
El "machismo latinoamericano" y sus derivas en la educación internacional: reflexiones de estudiantes estadounidenses en Buenos Aires
}

\begin{abstract}
Resumen
Este artículo analiza las representaciones y experiencias de jóvenes estadounidenses participantes de un programa de educación internacional en Buenos Aires, en relación con los modelos, representaciones y relaciones de género y de sexualidad que observan y viven en la cultura local argentina. Con una metodología cualitativa, entre 2012 y 2014, se recogieron testimonios escritos y orales de 50 estudiantes, varones y mujeres, sobre temas como los piropos/acoso callejero, el machismo latinoamericano, el amamantamiento en público, los ideales corporales, cuestiones que permitieron reflexionar sobre estereotipos culturales en los que confluyen el género, la etnicidad, la clase y la nacionalidad.
\end{abstract}

\section{Palabras clave}

Educación intercultural; Argentina; Estados Unidos; género; sexualidad; América Latina doi: 10.11144/Javeriana.m9-18.mlde

Escrito por Karina FeLITTI Consejo Nacional de Investigaciones Cientificas y Técnicas, CONICET Buenos Aires, Argentina karinafelitti@gmail.com

Andrea Rizzotti Área de Estudios Latinoamericanos Facultad latinoamericana de Ciencias Sociales, flacso

Buenos Aires, Argentina andrearizzotti@gmail.com

\section{Transferencia a la práctica}

Este estudio exploratorio indaga en las dinámicas de interacción que se dan entre los estudiantes internacionales y la cultura local argentina, desde los aportes de los estudios culturales y los estudios de género y sexualidad. Nuestro objetivo de transferencia es generar conocimiento que permita diseñar herramientas que motiven la inmersión cultural. Al invitar a los estudiantes a reflexionar, debatir y participar en acciones por la equidad de género buscamos poner en práctica una concepción de la educación intercultural basada en el "hacer juntos" como parte sustancial de la propuesta de intercambio.

Para citar este artículo / To cite this article / Pour citer cet article / Para citar este artigo

Felitti, K. \& Rizzotti, A. (2016). El "machismo latinoamericano" y sus derivas en la educación internacional: reflexiones de estudiantes estadounidenses en Buenos Aires. magis, Revista Internacional de Investigación en Educación, 9(18), 13-28. http://dx.doi.org/10.11144/Javeriana.m9-18.mlde 


\section{Keywords}

Intercultural education; Argentina; U.S

gender; sexuality; Latin America

\section{Abstract}

This article analyzes the representations and experiences of young Americans participating in a program of international education in Buenos Aires, in relation to the models, representations and gender and sexuality issues they observe and live in the local culture from Argentina. With a qualitative methodology between 2012 and 2014, written and ora testimonies of 50 students (men and women) were collected. These testimonies reflected on topics such as compliments / street harassment, Latinamerican machismo, breastfeeding in public spaces, and body ideals. These issues allowed us to reflect about cultural stereotypes in which gender, ethnicity, class and na tionality converge.

\section{Transfer to practice}

This study investigates the dynamics of interaction between international students and the local Argentine culture, from the contributions of cultural studies and studies on gender and sexuality. Our goal is to generate knowledge that allows us to design tools that motivate a cultural immersion. By inviting students to reflect, debate and participate in actions to reach gender equity we seek to put into practice a conception of intercultural education based on "doing together", which is a substantial part of the exchange.

\section{Mots clés}

Education interculturelle; Argentine; Etats-Unis; genre, sexualité; Amérique Latine

\section{Résumé}

Cet article analyse les représentations et les expériences de jeunes américains participants d'un programme d'éducation internationale à Buenos Aires, par rapport aux modèles, représentations et les rapports de genre et de sexualité qu'on observe et vive dans la culture locale argentine. Avec une méthodologie qualitative, entre 2012 et 2014, on a recueilli les témoignages écrits et oraux de 50 étudiants, hommes et femmes, par rapport aux sujets tels que les galanteries/harcèlements dans les rues, le machisme en Amérique du sud, l'allaitement en public, les idéelles corporelles, ces aspects nous ont permis réfléchir par rapports aux stéréotypes culturels dans lesquels convergent le genre, l'ethnicité, la classe, et la nationalité

\section{Transfert à la pratique}

Cette étude explore les dynamiques d'interaction qui existent entre les étudiants internationales et la culture locale argentine, depuis les contributions des études culturelles et les études de genre et de sexualité. Notre objectif de transfert est celui de produire de la connaissance pour dessiner des outils qui encouragent l'immersion culturelle. En invitant aux étudiants à réfléchir, discuter et participer par rapport aux actions pour l'équité de genre on cherche mettre en pratique une conception de l'éducation interculturelle fondée sur «le faire ensembles» en tant que partie substantielle du projet d'échange.

\section{Palavras-chave}

Educação intercultural; Argentina; Estados Unidos; gênero; sexualidade; América Latina

\section{Resumo}

Este artigo analisa as representações e as experiências de jovens estadunidenses participantes de um programa de educação internacional em Buenos Aires, com relação aos modelos, representações e relações de gênero e de sexualidade que observam e vivem na cultura local argentina. Com uma metodologia qualitativa, recolheram-se depoimentos escritos e orais de 50 estudantes, homens e mulheres, entre 2012 e 2014, sobre temas como as paqueras/assédio de rua, o machismo latino-americano, a amamentação em público os ideais corporais, questões que permitiram refletir sobre estereótipos culturais nos quais confluem o gênero, o étnico, a classe e a nacionalidade.

\section{Transferência à prática}

Este estudo exploratório indaga as dinâmicas de interação existentes entre os estudantes internacionais e a cultura local argentina, a partir das contribuições dos estudos culturais e dos estudos de gênero e sexualidade. Nosso objetivo de transferência é gerar conhecimento que permita desenhar ferramentas que motivem a imersão cultural. Ao convidar aos estudantes a refletir, debater e participar em ações pela equidade de gênero, procuramos pôr em prática uma concepção da educação intercultural baseada no "fazer juntos" como parte substancial da proposta de intercâmbio. 


\section{Introducción}

Las representaciones son algo más que un conjunto de ideas que tenemos acerca de las otras personas; son conceptos históricos que se dirigen hacia nosotros y nos interpelan para fundar tipos de sujetos, para decir cómo es la gente y cómo no es. Las representaciones sociales, como sistemas de interpretación que rigen nuestra relación en el mundo y con los otros, orientan y organizan las conductas y las comunicaciones; llegan como imágenes y como una vía para conocer a las personas, sin que importe demasiado si este conocimiento se da gracias a la experiencia empírica. En suma, la representación es un medio de conocimiento del mundo y de los sujetos, a la vez que un medio de significación constitutiva de ellos, de ahí que pueda ser entendida como contenido y también como proceso (Rodríguez-Rondón, 2006).

Las imágenes que se construyen en Estados Unidos sobre América Latina en general corresponden a las formas en que se entienden las relaciones entre ambos: en torno a la idea de un "hemisferio occidental", desde la supuesta irrelevancia de la región para Washington y, opuesta a esta última, para destacar la voluntad y práctica imperialista estadounidense (Russell, 2006). Estas relaciones han ido cambiando con la historia y los distintos gobiernos estadounidenses y latinoamericanos en particular, como sucedió durante los años 40 cuando se privilegió una imagen de "buenos vecinos"1. En el caso del cine de Hollywood, la representación de lo latino suele remitir a varones delincuentes, traficantes, vagos, oportunistas, sucios y violentos (Bailey, 1989; Ramírez-Berg, 2000) que van construyendo una noción de "machismo" asociada a estos países.

De acuerdo a la Real Academia Española, el machismo es una "actitud de prepotencia de los varones respecto de las mujeres". Esta definición se expresa, por ejemplo, en las dificultades que experimentan las mujeres para llegar y permanecer en espacios de decisión, la violencia de varones hacia mujeres o también de varones hacia otros varones que no encajan en el modelo de masculinidad hegemónica. En un trabajo exploratorio previo, analizamos las imágenes de América Latina que presentaban las universidades de Estados Unidos en los materiales informativos sobre posibles destinos de educación internacional. En ellos, las advertencias sobre el machismo y sus manifestaciones cotidianas como el piropo ocupaban un lugar destacado (Felitti \& Rizzotti, 2013)². En estas publicaciones, machismo está escrito en español por no encontrar una palabra equivalente en inglés, hecho que confirmaba la supuesta originalidad de estas conductas. En ese primer estudio exploratorio, relevamos las opiniones y experiencias de estudiantes estadounidenses de dos programas de intercambio radicados en Buenos

1 Un ejemplo de esta política es la película Saludos, Amigos (Hello, Friends) producida por Walt Disney Pictures en 1943, por pedido del Departamento de Estado en el marco de su política de buena vecindad. Ambientada en varios lugares de América del Sur y con la combinación de la acción-real y la animación, muestra a bailarinas del carnaval de Río de Janeiro, gauchos pampeanos montando a caballo e indígenas peruanos con sus llamas. Para Julianne Burton-Carvajal (1994), este film, como otros encargados por el Departamento de Estado, estuvieron diseñados desde una mirada colonial. Además, al utilizar dibujos animados y personajes de películas infantiles ejercían una forma de paternalismo e infantilización del auditorio.

2 Es interesante reflexionar cómo se da la situación inversa, es decir, cómo se presenta a Estados Unidos y a los estadounidenses a los viajeros latinoamericanos. Individualismo, independencia, autoconfianza, franqueza, informalidad, competencia y realización personal, éxito material, puntualidad, energía y etnocentrismo son algunas de las características que enumeran los sitios web Me quiero ir, www.mequieroir.com/ y Guía estudiantil internacional, www. guiaestudiantilinternacional.com/
Descripción del artículo | Article description | Description de l'article | Artigo descrição

Este artículo se deriva de la investigación "¿Qué ven cuando nos ven? Opiniones, valores y experiencias de jóvenes estadounidenses en torno al cuerpo, el género y la sexualidad durante su estancia estudiantil en Argentina" en la que se analiza las representaciones y experiencias de estudiantes estadounidenses que realizan estancias breves de educación internacional en Buenos Aires, Argentina, sobre el machismo latinoamericano y otras situaciones que ellos mismos indican como modos particulares de entender el cuerpo, el género y la sexualidad en la cultura local. Entre 2012 y 2014, se recogieron testimonios escritos y orales de 50 varones y mujeres jóvenes sobre temas como los piropos, el amamantamiento en público, la libertad sexual, las políticas de equidad de género en el país. Con esta investigación, proponemos poner en relación los estudios sobre el género y las sexualidades con los estudios de educación internacional y, de ese modo, visibilizar situaciones que suelen soslayarse o reducirse a consejos prácticos para "lidiar" con el machismo latinoamericano y no para comprender socioculturalmente el fenómeno, y conocer las acciones locales que se desarrollan para revertir el sexismo e invitarlos a participar de ellas. 
Aires en relación con cuestiones vinculadas directamente con el género y la sexualidad. En esas entrevistas, pudimos identificar una serie de situaciones recurrentes: el enojo con el piropo y lo llamativas que resultaban la fluidez del lenguaje corporal, las manifestaciones de afecto en público y la dedicación que la mayoría de las mujeres ponían en su arreglo personal.

En la investigación que actualmente estamos desarrollando, buscamos profundizar en algunos de los temas que emergieron en la etapa exploratoria. Nos moviliza, por un lado, conocer las formas en que se tejen las representaciones sobre lo latinoamericano en torno al género y la sexualidad, principalmente la circulación de la idea de machismo entre los estudiantes y la negociación que establecen con esa representación una vez que están instalados en Buenos Aires e interactúan de modo presencial y personal con la cultura local. Por otra parte, consideramos que sus opiniones y experiencias nos permiten acceder a otros sentidos de nuestra propia identidad, que por su cotidianeidad pueden soslayarse o permanecer invisibles. A partir de estos intercambios, ponemos contenido práctico a nuestra propuesta de educación intercultural. En América Latina, esta suele concentrarse en espacios en los que la diversidad está definida por la diferenciación étnica —en términos de población indígena o pueblos originarios - que frecuentemente vincula categorías estáticas y esencialistas de identidad y cultura (Diez, 2004). Aquí partimos de considerar que la educación internacional puede ser también una forma de educación intercultural, es decir, una propuesta educativa que valore la diversidad y que resulte relevante para todos los participantes, más allá de las posiciones de mayoría y minoría.

El foco de este artículo está puesto en las valoraciones de un grupo de estudiantes estadounidenses respecto a la circulación de los cuerpos en el espacio público de Buenos Aires: ¿qué diferencias perciben en las formas de mirar/se en Buenos Aires? ¿Qué sienten cuando observan a una madre amamantando a su bebé en el subte (metro, subterráneo) o a parejas de géneros indistintos besándose apasionadamente en la calle? ¿Qué ideas se activan respecto al machismo latinoamericano cuando un desconocido opina sobre el aspecto físico de las jóvenes? ¿Cómo son vividas estas experiencias por la diversidad que implica la propia categoría "estudiantes estadounidenses" (si es una mujer, un varón, hetero/bi/gay/lesbiana, latino, religioso, etc.)?

Llevamos a cabo un estudio exploratorio con un enfoque epistemológico interpretativo y una estrategia metodológica cualitativa. Esto implica recrear lo que los actores sociales piensan, creen y hacen. Consideramos que la investigación cualitativa resulta la forma adecuada de acercamiento cuando se busca conocer la interpretación de los actores desde su experiencia (Szasz \& Amuchástegui, 1996, p. 22) y cómo estas interpretaciones afectan sus comportamientos e interacciones sociales. Utilizamos dos técnicas de producción de la información: entrevistas semiestructuradas individuales, dirigidas a indagar los saberes, significados y las prácticas desde su conexión con las distintas experiencias personales y grupos de discusión orientados a rastrear creencias y opiniones sedimentadas y consensuadas, para distinguirlas de aquellos puntos donde hay mayor polémica, y ubicar las posturas en conflicto. Para la realización de las entrevistas semiestructuradas y la moderación de los grupos de discusión, elaboramos sendas guías de pautas de acuerdo a los objetivos de la investigación y las dimensiones de análisis previstas.

Entre 2012 y 2014, recolectamos, sistematizamos y analizamos testimonios escritos y orales de 50 estudiantes del programa de Liberal Arts del Council on International Education Exchange, CIEE, en el Study 
Center de Buenos Aires, que tomaron el curso semestral Cuerpos, géneros y sexualidades en la Argentina, del cual somos docentes. Los estudiantes nacieron en diferentes lugares de Estados Unidos y estudian en diversas universidades de ese país, lo que otorga una importante heterogeneidad a la muestra, que en esta ocasión no se pondera salvo en el caso de un estudiante que explícitamente hace mención de su condición de latino. La prioridad en este trabajo estuvo puesta en lo homogéneo de sus saberes previos sobre las relaciones de género y sexualidad en Argentina y el machismo latinoamericano, más que en la heterogeneidad de la condición de "estadounidense". Sus edades oscilan entre 20 y 24 años y pertenecen a las clases media y media alta, con padres profesionales ${ }^{3}$.

Las entrevistas tuvieron un carácter semiestructurado, es decir, dejamos espacio para que pudieran expresarse libremente pero también propusimos una serie de preguntas que se repitieron en todos los casos. Para este artículo, tomamos en consideración las respuestas a dos de ellas: qué les resultaba más llamativo en la cultura local en cuestiones que involucraran el cuerpo, el género y las sexualidades, y qué ideas y representaciones del machismo latinoamericano tenían antes de llegar a Buenos Aires y cuánto de ellas se sostuvieron, resignificaron o abandonaron durante sus estancias. Estas dos cuestiones organizan los dos apartados de este artículo: Las miradas no solicitadas y el machismo latinoamericano y Cuerpos y afectos en el espacio público.

En cuanto al procesamiento de los datos, los testimonios orales fueron transcriptos del modo más literal posible. Esto se hizo a medida que se realizaban los encuentros para facilitar un análisis simultáneo y eventuales reorientaciones de las indagaciones. Nuestras interpretaciones fueron orientadas en función de la perspectiva de las personas investigadas, con el reconocimiento de que sus testimonios ya son en sí mismos interpretaciones de primer orden (Geertz, 1987, p. 28). Sabemos que el hecho de analizar las opiniones y experiencias de estudiantes de nuestro propio curso tiene un sesgo, dado por las relaciones de poder que se dan entre profesor y alumno pero también presentaba oportunidades valiosas. Una de ellas fue la posibilidad de generar un entorno de confianza por la frecuencia de los encuentros en clase y otras actividades del programa. La otra fue poder observar transformaciones a lo largo del semestre y a partir de ellas, postular una nueva hipótesis sobre las implicancias de trabajar temas de género con los estudiantes de intercambio como parte de su formación.

Lo que sigue son los resultados de esta primera etapa de trabajo, que tiene la intención de hacer un aporte al campo de la educación internacional desde este enfoque que pone el cuerpo, el género y las sexualidades en un lugar destacado.

\section{Las miradas no solicitadas y el machismo latinoamericano}

Desde nuestra experiencia, cada estudiante que llega a Buenos Aires por un semestre o dos, desarrolla una mirada que se asemeja a la del antropólogo: vive un sistema de signos y se relaciona primero con sus significantes pero sin comprender del todo sus significados (Lins-Ribero, 1989). Cuando los estudiantes opinan sobre "nuestra" realidad (lo exótico para ellos), permiten que nosotras como docentes e investigadoras volvamos exótico lo que vivimos todos los días y asumamos una posición de extrañamiento. De esa forma, podemos cuestionar la conciencia práctica sobre la

3 Para preservar el anonimato, utilizamos solo las iniciales de sus nombres e indicamos si es un varón o una mujer y el semestre de su estancia. 
que habla Anthony Giddens (1995), esa que remite a lo dado, lo rutinario. Ella es fuente básica de la reproducción de la vida social y crea la confianza en que los parámetros de monitoreo mutuo de las acciones están presentes (Lins-Ribeiro, 1989). La rutina y la previsibilidad son fuentes de seguridad, una sensación que justamente no tienen los estudiantes estadounidenses por ser foráneos. Al no participar de la conciencia práctica, el extrañamiento se produce objetivamente en ellos, ya que los supuestos del cotidiano no lo son para ellos.

Los estudios sobre la comunicación no verbal y la diversidad cultural permiten situar los significados de prácticas como establecer contacto visual con otra persona (eye contact) en diferentes contextos. En Estados Unidos, el hecho de mirar a una persona a los ojos puede ser visto como una señal de respeto siempre y cuando no se fije la mirada y esta sea moderada (salvo situaciones específicas en las que se requiere una mayor intensidad, por ejemplo, en el mundo de los negocios). En la ciudad de Buenos Aires, el contacto visual no aparece como una cuestión sobre la que hay que hablar en la socialización temprana. Sin embargo, para quienes sí han sido educados en una pedagogía del mirar (a quiénes, por cuánto tiempo, en qué circunstancias) hay situaciones que pueden resultar llamativas y, a veces, hasta incómodas:

...los varones acá en Argentina nos miran fijamente. Tal vez porque somos extranjeras y rubias o porque es una expresión cultural, pero no se considera grosero o incivil como en los Estados Unidos (M., mujer, septiembre de 2014).

Algo similar sostiene otra estudiante, que ya no ve fallas en el proceso de civilización pero sí falta de cortesía:

En los Estados Unidos, mirar fijamente se considera descortés. Cuando niña, mis padres me decían 'no apuntes' hacia alguien y 'no mires a esa persona'. En Argentina, esas normas no se aplican. En el subte, todos miran fijamente a las personas (L., mujer, agosto de 2014).

Las miradas masculinas en particular son las que apoyan una de las representaciones más típicas de la masculinidad de América Latina, el machismo, y las que dan origen a su manifestación más estridente: el piropo o el acoso callejero, dependiendo del marco teórico y político desde el cual lo analicemos ${ }^{4}$. Como ya indicamos, la mayoría de las estudiantes viven esta escena con malestar, incomodidad y, a veces, miedo. Hay algunas que distinguen entre los piropos abusivos y ofensivos, y otras que los ven como parte de la cultura local y no se inquietan demasiado. Como nos dijo una de ellas:

Hay una frontera borrosa entre el piropo como abuso y como expresión cultural (L., mujer, agosto de 2014).

4 La Real Academia Española define la palabra "piropo" como "lisonja, requiebro"; "alabanza afectada para ganar la voluntad de alguien" o como "lisonjear a una mujer, alabando sus atractivos". Algunos sostienen que el término viene del latín pyrōpus, una piedra similar al rubí que los enamorados entregaban a sus novias para agasajarlas. Aquellos que no tenían dinero para adquirirlas utilizaban elogios orales para ganar el cariño de sus compañeras. De esa manera, la palabra tomó el lugar y el nombre de la piedra. El acoso callejero se define, en cambio, como una situación en la cual uno o más hombres extraños acosan a una o más mujeres en un lugar público que no es el lugar de trabajo de la mujer (eso sería acoso laboral). Ya sea con miradas, palabras, gestos o acciones directas, el hombre afirma su derecho a entrometerse en la atención de la mujer, a la vez que la define como un objeto sexual y la obliga a interactuar con él (Lichinizer, 2014). 
Las que viven o estudian en grandes ciudades en Estados Unidos han recibido también allí comentarios sobre su cuerpo, aunque no por ello dejan de molestarse cuando esto les sucede en Buenos Aires:

Dondequiera que vaya, veo cómo los hombres miran y comentan a las mujeres. Al principio, pensé que [me] miran porque podrían decir que no era de aquí. Traté de justificarlo como una parte de la cultura o algo que pasa en las ciudades. Soy de Nueva York donde los piropos también ocurren pero en una cantidad más pequeña (V., mujer, agosto de 2014).

Para algunas, por lo contrario, en Buenos Aires han recibido por primera vez un piropo. Aquellas que provienen de familias latinas los experimentan de una forma específica, no ven el hecho como algo tan extraño, y quienes viven en la zona de frontera con México parecen molestarse menos, no porque les guste sino más bien por costumbre:

Yo vivo en Nuevo México, estoy acostumbrada (T., mujer, agosto de 2014).

Lo interesante es que aun quienes ya vivieron estas situaciones en Estados Unidos, tienden a resaltar las diferencias entre lo que sucede en Buenos Aires y esas experiencias anteriores. Al asumir esta posición, la diferencia cultural aparece como variable explicativa: el piropo es una muestra de la cultura machista latinoamericana, que se expresa en las demostraciones públicas y violentas de los varones hacia las mujeres y la subordinación de ellas.

De acuerdo a la investigadora colombiana Mara Viveros-Vigoya, el machismo ha sido definido como la obsesión masculina con el predominio y la virilidad, que tiene expresión en la posesividad respecto de la propia mujer y en actos de agresión y jactancia en relación con otros hombres (Viveros-Vigoya, 2006). Este término utilizado inicialmente y de modo ambiguo en relación con las representaciones de hombría de los varones mexicanos, se ha convertido en el lenguaje corriente en un sinónimo de la masculinidad latinoamericana, tanto para la academia como para el activismo, sin que circule una reflexión sobre los orígenes, usos y abusos del término (Gutmann, 1996). Matthew C. Gutmann (1998) ha señalado que la figura del macho coincide con la del emigrante mexicano en Estados Unidos, al cual se le adjudican una violencia y una sexualidad incontrolables. Esto construye una imagen que sirve para clasificar y descalificar a los hombres de acuerdo con su supuesto carácter nacional y racial inherente. De este modo, el machismo permite actualmente a los estadounidenses hacer generalizaciones peyorativas sobre rasgos supuestamente culturales de los hombres mexicanos — por extensión, latinoamericanos-, convertidos así en encarnaciones de la alteridad. Además, posibilita hacer gradaciones entre lo superior y lo inferior, en las cuales se superponen colores de piel y comportamientos sexuales.

Por su parte, Mara Viveros-Vigoya (2006) retoma las explicaciones de diferentes autores que sitúan el machismo en relación con el trauma de la Conquista, el mestizaje, la traición de Malinche ${ }^{5}$ y el mundo latinoamericano mestizo, y lo postulan como una organización social fruto de la violación en la que se perpetúa y legitima constantemente la superioridad masculina y europea. De esta forma, el machismo puede ser pensado como un comportamiento que no solo hace referencia a una dominación de género sino también a jerarquías entre sociedades, culturas y grupos étnicos raciales.

Mientras en algunos casos esto ha implicado la feminización de los hombres de los grupos racializados, en otros ha significado, por el contrario, la atribución de rasgos de hipervirilidad, estimada negativamente desde el modelo de la masculinidad hegemónica. De ahí la necesidad de pensar el machismo latinoamericano como el resultado de prejuicios etnocéntricos y de la fabricación de imágenes nacionales difundidas por los medios de comunicación (Fuller, 1998). Diversas investigaciones (Archetti, 1998; Figueroa \& Salguero, 2014; Gutmann, 1998, 1996, Gutmann \& Viveros, 2007; Viveros-Vigoya, 2006) demuestran hasta qué punto las identidades masculinas latinoamericanas son múltiples y diversas, y no aptas para generalizaciones.

De ahí que el machismo latinoamericano sea una noción con muy corto alcance analítico y explicativo para dar cuenta de los fundamentos simbólicos y sociales de la dominación masculina en América Latina. Más bien, se trata de un término mistificador que permite naturalizar el comportamiento de los varones de los grupos sociales subalternos (ya sea por su clase o su origen étnico racial) y calificarlo como poco civilizado e incapaz de adoptar los comportamientos y valores propios de una ética moderna y modernizante, propia de los hombres de los grupos sociales dominantes.

Este machismo tiene como contracara la figura de la "mujer sumisa". Evelyn Stevens (1977) acuñó el término "marianismo" para designar el culto a la superioridad espiritual femenina, que predica que ellas son moralmente superiores y más fuertes que los varones. En esta lectura, el culto a la virgen María proporcionaría un patrón de creencias y prácticas, una fuerza espiritual que propicia la abnegación. Para Evelyn Stevens,

5 Sobre Malinche, ver Jean Franco (abril de 1995). La Malinche: del don al contrato sexual. Debate Feminista, 11, 251-270. Gloria Elena Bernal (trad.). Recuperado de http://www.debatefeminista.pueg. unam.mx/wp-content/uploads/2016/03/articulos/011_13.pdf 
esto explicaría la aceptación femenina del machismo y de su posición social subalterna en el espacio público, que se ve compensada por un rol clave en el hogar. Norma Fuller (1995) critica esta construcción y la del machismo, al considerar que ambas terminan por ser caricaturas que no dan cuenta de la diversidad que hay entre los países de la región y en cada uno de ellos.

La explicación cultural que vehiculiza el machismo y el marianismo, y que toma como ejemplo paradigmático el piropo o acoso callejero, desconoce dos situaciones. Por un lado, la existencia en América Latina de resistencias organizadas al acoso callejero ${ }^{6}$ y de otras manifestaciones informales que se van extendiendo entre las mujeres. Por otra parte, estos enfoques tampoco dan cuenta de la existencia del acoso callejero en Estados Unidos ${ }^{7}$, ni de las organizaciones que allí también lo combaten ${ }^{8}$, ni del grave problema de las violaciones que suceden en los campus universitarios. Pese a que estos hechos se inscriben claramente dentro de la violencia de género, cuando hablamos del machismo durante los talleres o en el marco del curso de género que dictamos, solo en dos ocasiones se hizo referencia a ellos:

Sé que no es solo mi propio problema y que hay un movimiento de mujeres en Argentina que quieren un cambio de esta parte de la cultura (K., mujer, noviembre de 2011).

6 En Chile, en noviembre de 2013, se creó el Observatorio contra el Acoso Callejero (OCAC), conformado por un equipo de abogados que propuso un proyecto de ley con el fin de establecer los parámetros del hostigamiento en la calle y fijar penas. En 2012, estudiantes de la Universidad Católica de Perú dieron vida a Paremos el acoso callejero. Observatorio virtual, un estudio sobre acoso callejero en Lima y el Callao (Vallejo-Rivera \& Rivarola-Monzón, 2013). Paraguay fue el primer país latinoamericano que ideó un proyecto que exige una pena de hasta 180 días de cárcel a quien "dirija palabras o acciones con connotación sexual a una mujer con quien no mantiene relación de ninguna índole, en lugares o espacios públicos". En Argentina, Acción Respeto se dedica a pegar carteles en las calles y a hablar con los transeúntes para explicarles por qué consideran necesario actuar contra el hostigamiento callejero.

7 Por ejemplo, en 2014, Stop Street Harassment realizó una representativa encuesta en Estados Unidos, a 2.000 personas, que indicó que el $65 \%$ de las mujeres había experimentado acoso en la calle; el $23 \%$ había sido tocada sexualmente, el $20 \%$ había sido seguida y el $9 \%$ se había visto forzada a hacer algo sexual. Entre los hombres, el $25 \%$ había sido víctima de acoso callejero (un mayor porcentaje de hombres identificados como LGBT) y su forma más común habían sido los insultos contra homosexuales y transexuales (9\%) (Stop Street Harassment, 2014).

8 Por ejemplo, Stop Telling Women to Smile es un proyecto de arte que consiste en poner en espacios públicos, retratos de mujeres con leyendas que hablan directamente a los acosadores. Cards against Harassment es el proyecto de una mujer de Minneapolis, que creó tarjetas con frases que una víctima de acoso callejero puede dar al perpetrador. Están diseñadas para que una persona pueda responder en una manera tranquila — para evitar la escalada de la situación-y superar los sentimientos de impotencia.
No podemos solo ver el tema del piropo sin tener en cuenta lo que sucede en los campus con las violaciones (M., mujer, julio de 2014).

Cuando se dio esta reflexión sobre las violaciones, el problema fue visto como una consecuencia del exceso de alcohol y no como el corolario posible de la inequidad entre mujeres y varones. Cuando ponemos a discusión estos temas, emerge una pregunta acerca de la igualdad y la diferencia: ¿el enojo y el rechazo que sienten las jóvenes estadounidenses ante el piropo se apoya en razones similares a las que manifiestan las mujeres latinoamericanas? En el caso de las estudiantes, la experiencia de ser extranjeras le da una especificidad a la escena y es justamente esa característica la que hace que los significantes se vuelvan difusos:

En los Estados Unidos, estoy acostumbrada a pensar que cualquier piropo es una manifestación de objetivación de las mujeres. Acá tengo que preguntarme si necesariamente los piropos implican la objetivación (A., mujer, agosto de 2013).

El piropo o acoso callejero pone en juego entonces dos valores muy importantes para la cultura de estas jóvenes: la autodeterminación personal y la igualdad. Lo primero es compartido por mujeres de diferentes contextos, ya que está comprobado que las mujeres ven afectadas sus decisiones por temor al acoso (la ropa que llevan, los recorridos que hacen, las horas a las que salen):

Cada mañana cuando me visto, tengo que pensar si es apropiado llevar cualquier ropa, cosas que llevo todo el tiempo en los Estados Unidos sin problema. Nunca he pensado antes si es demasiado peligroso llevar una falda por la noche cuando tengo que caminar sola por un rato (K., mujer, noviembre de 2013).

Lo segundo, la igualdad de género, tiene un significado particular en la cultura estadounidense. Estas jóvenes están socializadas en una cultura que constantemente les dice que el éxito es cuestión de voluntad. A su vez, en Estados Unidos no hay una licencia por maternidad paga, porque, entre otras razones, se considera que una medida así cuestionaría la igualdad de las mujeres. Así, la valoración del esfuerzo personal y el fuerte rechazo a toda situación que roce la discriminación —incluso la que se considera "positiva" - marcan una diferencia. Esto también se expresa en situaciones cotidianas, como cuando algunas estudiantes rechazan que les cedan el asiento en el transporte público o que personas desconocidas ofrezcan pagarles un trago: 
No me gusta que los hombres que no conozco hagan cosas por mí, solamente porque soy una mujer y les parezco linda. Soy una persona y no algo para mirar (M., mujer, marzo de 2014).

Sin embargo, no todas opinan del mismo modo. Una joven valoró que su "novio argentino" la acompañara a su casa luego de una salida o que fuera él quien caminara por la vereda del lado en que circulan los automóviles como un gesto de protección, actitudes que jamás había visto en varones estadounidenses. Según ella: "si eso es machismo, sería un machismo positivo" (J., mujer, noviembre de 2014). El piropo, en cambio, era la expresión del machismo negativo, ya que reforzaba "el poder de dominación de los hombres a las sexualidades de las mujeres, porque casi todos los comentarios tienen una base sexual".

Para concluir este apartado, cuando las definiciones del "machismo" que las estudiantes traen consigo y las experiencias concretas que viven durante la estancia se ponen en discusión, algunas de las representaciones iniciales se modifican y otras logran ubicarse en un contexto más amplio. En el marco del curso que dictamos, planteamos la lectura de algunos de los textos que aquí citamos y hacemos un análisis en clase de las situaciones que han vivido en Buenos Aires y de aquellas que conocen de Estados Unidos en relación con la desigualdad de género y la violencia. A partir de estas actividades, la mayoría termina por señalar que lo que se engloba bajo el término machismo, no pertenece a situaciones que solo ocurren en América Latina sino que corresponde a esquemas de poder que trascienden fronteras.

Un estudiante estadounidense, hijo de un guatemalteco y una mexicana, reconoció que llegar a Buenos Aires y pasar un tiempo largo en un país latinoamericano fue revolucionario y revelador:

Por primera vez, pude entender muchas cosas que no entendía. Aprendí que los hombres en Latinoamérica quizás sí son más persistentes, que quizás sí encajan más en la personalidad del proveedor de la familia; pero también aprendí que ese hombre machista tan estereotipado no es el único tipo de hombre que hay en Latinoamérica sino que al igual a otros países, hay variedad y el hombre latino no es uno solo: tenemos la decisión y opción para elegir qué tipo de hombre queremos ser. El machismo es lo construido, la percepción que se construyó a través de discursos prejuiciosos y estereotipados (J., varón, noviembre de 2014).

El análisis de la historia política y social de la Argentina, de sus luchas por los derechos humanos y de los avances logrados en las últimas décadas con políticas de equidad de género y el reconocimiento de varios derechos sexuales y reproductivos, les permitió también cuestionar el supuesto "marianismo" de las sociedades latinoamericanas.

Es posible ser exitosa sin un hombre, como se puede ver en mi madre anfitriona que es también una madre soltera. Además, se puede ver a las mujeres con un esfuerzo fuerte en la esfera política, como lo visto en las Abuelas y las Madres de Plaza de Mayo. Entonces, el 'machismo latinoamericano' existe pero no es un obstáculo demasiado grande para las mujeres latinoamericanas (J., mujer, noviembre de 2014).

Lo que me interesa mucho es la fuerza y confianza que veo en mis compañeras de clase en la Universidad de Buenos Aires y en otras jóvenes en la ciudad. Exudan una energía de poder, y de dignidad que mis compañeras 
francesas y estadounidenses no tienen. Participan mucho más en clases donde hay chicos y con mucha más confianza que mis otras compañeras. Pienso que el machismo no tiene solo efectos negativos. Hay una reacción femenina de parte de las mujeres que viven rodeadas por el machismo, que les hace tener una fuerza enorme. Aunque la sociedad argentina es la sociedad más 'machista' que conozco, es también la sociedad que tiene el grupo de mujeres más fuerte" (Z., mujer, noviembre de 2014).

\section{Cuerpos y afectos en el espacio público}

Como ya vimos, la idea del cuerpo como propiedad privada está muy presente en varias de las estudiantes. Claramente, esto no es privativo de Estados Unidos. A partir de la modernidad, el cuerpo expone una ruptura de los sujetos con los otros, con el cosmos, consigo mismo; se habla de poseer un cuerpo más que de ser un cuerpo. Esta concepción está vinculada con el ascenso del individualismo como estructura social, la emergencia del pensamiento racional y laico sobre la naturaleza, la represión de las tradiciones populares locales y el desarrollo de la medicina (Le Breton, 1995). Por eso, es posible hablar de la "liberación del cuerpo", si bien esta liberación es necesariamente parcial. Como sostiene Judith Butler (2006): "aunque luchemos por los derechos sobre nuestros propios cuerpos, los cuerpos por los que luchamos nunca son lo suficientemente nuestros. El cuerpo tiene una dimensión invariablemente pública. Constituido en la esfera pública como fenómeno social, mi cuerpo es y no es mío" (Butler, 2006, p. 52).

La consigna "mi cuerpo es mío" ha sido clave para el movimiento feminista, en especial en su segunda ola, pero también ha generado resistencias como una visión individualista y liberal del ser humano. Rosalind Pollack Petchesky (1995) ha planteado la posibilidad de pensar la propiedad como un derecho o una relación y no como una cosa. En otras culturas, la idea de propiedad implica una responsabilidad colectiva. De acuerdo a esta autora, en la obra de John Locke la propiedad del cuerpo está justificada por el hecho de ser dueño de cosas, pero la idea de ser dueño de su propio cuerpo se origina en Europa en el contexto de oposición a las relaciones de mercado y no en su defensa. Rosalind Pollack Petchesky examina la reapropiación que hicieron las feministas negras en Estados Unidos del modelo occidental de propiedad privada con sus nociones de maternidad como algo comunal; la integridad corporal que reclamaban no era individual ni estaba privatizada. Por eso, para ella, en lugar de abandonar el lenguaje de propiedad lo que deberíamos hacer es ampliar el marco de referencia.

Ese cuerpo personal expresa una sexualidad sobre la que se tiene derecho pero también hay límites (normativos, morales, religiosos). El umbral de lo permitido, aceptado y valorado cambia en cada cultura9. En Estados Unidos, los niveles de exposición de la intimidad son más bien bajos y esto constituye un tema de discusión pública con su propia denominación: Public Display of Affection, PDA, actos de intimidad física que se hacen a la vista de otros. Cuando los estudiantes comparan lo que ven en las calles de Buenos Aires con lo que conocen de su país, marcan diferencias notables.

9 En la antigüedad tardía, si un hombre soñaba que tenía relaciones sexuales con su madre esto podía ser un presagio de éxito político o comercial, a diferencia de una interpretación moderna occidental que sacaría conclusiones acerca de la psicología del soñador. El sexo en la antigua cultura helénica asumía una variedad de significados sociales y políticos, mientras que en el modelo actual la sexualidad es el centro de la personalidad y nos lleva a ver el sexo como la llave de entendimiento del individuo (Zeitlin, Winkler \& Halperin, 1990). 
Claro que en Estados Unidos también hay diferencias regionales y étnicas raciales; las demostraciones de afecto entre parejas del mismo sexo ${ }^{10} \mathrm{o}$ interraciales (Vaquera \& Kao, 2005) muchas veces implican otras dinámicas y estigmatizaciones.

(En los Estados Unidos) ... las parejas se dan la mano o besos pequeños pero en su mayor parte la demostración de afecto solo es realmente aceptable puertas adentro (...) Cuando yo estaba en un subte rodeada de novios y novias, cada uno de ellos muy abiertos con su afecto... Había besos largos y se sentaban en el regazo de uno al otro. No importaba que estuvieran en un lugar muy público (J., mujer, agosto de 2014).

En los Estados Unidos, la sexualidad usualmente permanece escondida. El amor romántico es solamente parte del hogar y le falta expresión pública... A diferencia de la gente porteña, que expresa el amor físico de una manera pública como un modo precioso de expresar la sexualidad, la cultura estadounidense reduce los cuerpos y la intimidad física como objetos avergonzados (L., mujer, marzo de 2014).

No hay necesidad de que las escenas sean de "alto voltaje" erótico. Los besos que se dan entre amigos ya resultan llamativos:

En los Estados Unidos, esta acción (besar) está reservada para la familia y mejores amigos y usualmente no entre dos hombres. Para mí, esta costumbre en la Argentina implica que hay gente que se sienta más cómoda con el contacto físico de una manera que no es sexual (A., varón, agosto de 2013).

En esta "cultura del beso", entienden que también hay reglas de género: "en el lenguaje escrito (del chat por ejemplo los chicos les envían un beso a otras chicas pero un abrazo a otros chicos" (T., mujer, noviembre de 2013). Esto pone en juego la idea de masculinidad y el rechazo al contacto corporal entre varones si no se quiere pasar por gay:

En los Estados Unidos, no es masculino estar tan cerca de otros hombres que no se conocen y se trata de no tener situaciones como esas. Acá no parece ser un problema no tener espacio personal (L., varón, agosto de 2013).

Las publicidades de ropa interior también llaman la atención de algunos estudiantes. Por un lado, porque les parece que los carteles tan grandes en las calles con mujeres publicitando lencería objetivan a las mujeres. Uno de ellos remarcó que si bien estos anuncios también pueden verse en las grandes ciudades de su país:

Algo que nunca he visto en un cartel en los Estados Unidos es la imagen de un niño que está llevando solamente la ropa interior... Él no está

10 Si bien la ley de matrimonio argentina reconoce a las parejas del mismo sexo, las demostraciones de afecto no heterosexuales aún pueden causar reacciones hostiles. Eso sucedió el 1 de noviembre de 2014 en una pizzería del centro de Buenos Aires: el mesero y el encargado del local les dijeron a dos chicas que dejaran de besarse porque ese era un "lugar familiar". Esta discriminación generó como respuesta una convocatoria por las redes sociales a hacer una gran "protesta de besos" en la puerta del local en donde sucedió el hecho. Se trató de una "besada colectiva" de homosexuales, lesbianas, bisexuales y trans para poner en evidencia el hecho de discriminación que había ocurrido (La Nación, 2014). Argentina, Ley 26.618, Código Civil. Modificación, Boletín Oficial, 21 de julio de 2010. Recuperado de http://servicios.infoleg.gob.ar/infoleglnternet/anexos/165000-169999/169608/norma.htm 
en una pose provocativa ni sexual pero en los Estados Unidos no se puede encontrar algo como esto (T., varón, agosto de 2014).

Pero si hay una escena que causa conmoción es el amamantamiento en espacios públicos. En Estados Unidos, si bien el sistema de salud recomienda la lactancia materna, hay estudios que indican que desde las políticas públicas se hace poco para facilitarla. Los obstáculos no solo tienen qué ver con la falta de apoyo en el trabajo (ya dijimos que no hay licencia por maternidad paga), sino con el tabú que significa dar el pecho en público. La construcción de esta práctica como algo femenino y privado es muy fuerte allí. Si bien no hay una normativa que lo prohíba, hay una zona de ambigüedad que deja en un lugar incierto a las mujeres que deciden hacerlo (Smith, Hausman \& Labbok, 2012). Estas ideas y experiencias previas chocan con la naturalidad que este comportamiento tiene en Buenos Aires y hasta llega a provocar molestia:

Me molesta debido al hecho de que en los Estados Unidos eso se ve como un acto muy privado solamente para casas o baños y entonces no estoy acostumbrada a mirarlo a diario. La primera vez que vi ese fenómeno yo estaba en el subte y no podía creer lo que veía... después de un momento me di cuenta [de] que no le molestaba a nadie más que a mí. Me enoja que yo me sienta tan incómoda en situaciones como esa, especialmente porque yo misma soy una mujer. Ahora me pregunto por qué razón en los Estados Unidos amamantar en público es algo tan tabú. Todavía me molesta cuando soy testigo de esto en las calles pero estoy acostumbrándome a mirar eso como parte de la vida (R., mujer, marzo de 2014).

Si una mujer estuviera lactando a su bebé en un subterráneo en los Estados Unidos sería algo horrible para muchas personas (...) La lactancia materna en los Estados Unidos es algo muy privado. Los pechos de las mujeres son algo bastante sexualizados y no representan más que el sexo. En Argentina, los pechos representan comida y vida para los bebés (...) Hay muchas mujeres en los Estados Unidos quienes están tratando de cambiar las leyes y las ideas de lactancia materna pero es algo sexual que no es fácil de cambiar (K., mujer, agosto de 2014).

Cabe destacar que el hecho de considerar la lactancia materna como algo "sucio" excede la cultura estadounidense. Los medios de comunicación han dado cuenta de mujeres que han sido reprendidas o invitadas a retirarse de determinados lugares por estar amamantando. En Argentina, la Ley 26.873 establece la promoción de la lactancia materna continuada y la alimentación complementaria oportuna para niños de hasta dos años de vida; la difusión y accesibilidad a la información a los efectos de la concientización pública, en especial de las mujeres embarazadas, y la promoción y apoyo a la creación de centros de lactancia materna y bancos de leche materna ${ }^{11}$. Esta norma no indica nada sobre la lactancia materna en espacios públicos, aunque no hay registros de inconvenientes con esta situación ${ }^{12}$. Uno de los lugares tabú han sido las iglesias católicas, aunque recientemente el Papa Francisco en medio de un bautismo colectivo en la Capilla Sixtina, trató de saldar esto al decir ante el copioso llanto de los niños: "Algunos llorarán porque están incómodos o porque tienen hambre... Si tienen hambre, madres, déjenlos comer, no hay problema, porque aquí, ellos son el enfoque principal" (CNN en español, 2014).

Incluso, la red social Facebook tuvo que hacer un cambio en su política contra la desnudez para permitir que las usuarias puedan compartir fotos del momento en que amamantan a sus hijos. Hasta hace poco, cualquier foto en que se pudiese ver el pezón de una mujer, aun en el caso de que se tratase de la imagen enternecedora de una madre y su hijo, era suspendida o borrada. Ahora la famosa red social cree que "la lactancia es algo hermoso y natural, y nos agrada saber que para las madres es importante compartir sus experiencias con otras personas en Facebook. La gran mayoría de estas fotos cumple nuestras políticas"13.

Todo esto nos confirma que las manifestaciones del cuerpo, su desnudez, su cercanía, su vestimenta y adornos, su contextura y la actitud de quien se construye en él, presentan variaciones culturales que deben ser tomadas en cuenta a la hora de diseñar los programas de educación internacional. La sexualidad, el género y el cuerpo son elementos clave de las experiencias abroad y durante el encuentro entre culturas muchas de las representaciones anteriores se modifican o adquieren otras significaciones.

\section{Conclusiones}

La educación internacional es un fenómeno que crece cada año. El progreso en las comunicaciones y el deseo de ser "ciudadanos del mundo" incentiva cada

11 Argentina, Ley 26.873, lactancia materna, promoción y concientización pública, Boletín Oficial, 5 de agosto de 2013. Recuperado de http://servicios.infoleg.gob.ar/infoleglnternet/ anexos/215000-219999/218212/norma.htm

12 En Chile, luego de la denuncia de una mujer a quien no se le permitió amamantar a su hijo en un restaurante de Valparaíso, diferentes asociaciones impulsaron un proyecto de ley y organizaron un "tetazo" en diferentes plazas del país (El Mirador de Sudamérica, 2014).

13 https://www.facebook.com/help/340974655932193/ 
vez a más jóvenes a salir a estudiar en el extranjero y conocer otras culturas. Por supuesto, el hecho de viajar no es algo nuevo pero sí lo es la posibilidad de hacerlo en un marco de "seguridad" que proteja nuestra "zona de confort". Esta premisa es muy importante para la mayoría de las empresas y de las universidades que proponen y difunden programas de Study Abroad. De ahí su preocupación por "advertir" sobre las diferencias y dar consejos para saber lidiar con ellas.

En la información que proveen las universidades y las empresas de Estados Unidos (aquellas que planifican intercambios — de estudio, trabajo - o simplemente turismo), América Latina es presentada desde el supuesto de su homogeneidad en varios aspectos. El español como lengua, la importancia del catolicismo, su informalidad comercial, el gran nivel de emocionalidad en el trato, la diversidad de sus paisajes, la riqueza de su arte, lo sabroso de sus comidas, la alegría de sus canciones y danzas, y la generosidad de sus habitantes. Todas estas imágenes construyen una visión folclorizada, unívoca y muchas veces ahistórica, que estereotipa y no deja lugar a la diferencia. En esas descripciones, el machismo aparece como una de las características negativas de la cultura latinoamericana. Sobre él no se entra en detalles, ni se explican sus posibles relaciones con la dominación colonial —situación compartida por los diversos países que conforman América Latina y que pese a su importancia no suele ser visibilizada —, más bien se dan pautas para aprender a convivir con él, entendiéndolo como una "diferencia cultural" que hay que tolerar.

En este estudio, analizamos las opiniones y experiencias de estudiantes estadounidenses en Buenos Aires sobre este tema, y otras cuestiones que ellos indicaron como "diferencia cultural" relacionadas con el cuerpo, el género y la sexualidad. Las manifestaciones de afecto en público, los saludos con un beso entre varones y el amamantamiento en espacios públicos estuvieron entre las más referidas. En relación con el machismo como categoría, en el marco del curso que ambas autoras dictamos, propusimos la lectura de textos producidos por especialistas latinoamericanos y algunos pocos estadounidenses, que señalaban lo incompleto que resultaba este concepto a la hora de explicar las relaciones de poder entre varones y mujeres, y las diferentes formas de ser hombre en la región. Lo mismo hicimos respecto al concepto de marianismo, supuesta contracara modélica para el éxito del dominio machista.

Más allá de las lecturas, invitamos a los estudiantes a reflexionar sobre sus propias experiencias con el machismo: ¿existe?, ¿cómo se manifiesta? Como vimos, los ejemplos giraron en torno al piropo o acoso callejero y su descripción como una escena molesta que restringía sus libertades (en la elección de la vestimenta, en el recorrido peatonal y el horario para realizarlo).

Durante los momentos de reflexión que pautamos para que discutieran en pequeños grupos sus propias opiniones y experiencias, la mayoría de los estudiantes pudieron contextualizar el machismo y visualizar en qué medida la dificultad de traducir la palabra al inglés hablaba de una construcción racializada del fenómeno, ajeno a la cultura anglosajona. En general, no se desestimó la existencia de machismo en América Latina pero sí se pensó que no era un fenómeno exclusivo de estos países y que con otras palabras podían expresarse desiguales relaciones de poder entre los géneros en cualquier otro lugar del mundo, incluyendo Estados Unidos.

En estas discusiones, fue llamativo el peso que se dio a la autonomía corporal y las libertades individuales que se definen corporalmente. El cuerpo, tal como corresponde al esquema de la Modernidad, es entendido por 
los estudiantes como una propiedad individual. En este esquema se da el problema del piropo/acoso: si este cuerpo es mío yo decido entonces quién puede mirarlo o decir algo sobre él. Como señalamos antes, siguiendo a Judith Butler, esta consigna de propiedad y autonomía no es fácilmente aplicable a la vida social. Existimos en la mirada de los otros. De ahí la importancia de reconsiderar las definiciones del cuerpo en el discurso liberal, que si bien sirve como plataforma para la exigencia de derechos, parte de construcciones arbitrarias y con bases excluyentes.

Si tenemos en cuenta los diferentes modos normativos y socioculturales de pensar y gestionar políticamente la equidad de género y los derechos sexuales y reproductivos que se dan en Estados Unidos y en Argentina, se abren nuevas posibilidades de indagación sobre las que ya estamos trabajando. El aborto, la prostitución, el matrimonio entre personas del mismo sexo, la subrogación de vientre, la transexualidad... son cuestiones con respuestas políticas diferentes en cada país. Sin embargo, hay discursos que nos ponen en contacto, hay traducciones, hay zonas de frontera, hay circulación de opiniones, experiencias y prácticas. De ahí nuestro interés en seguir avanzando en el análisis de las representaciones, de cómo nos ven, de quiénes somos y de qué modos podemos aprender y trabajar juntos para una mayor equidad en la diversidad.

\section{Sobre las autoras}

Karina Felitti es investigadora adjunta del Consejo Nacional de Investigaciones Científicas y Técnicas, CONICET-Argentina. Profesora del área de estudios latinoamericanos de la Facultad Latinoamericana de Ciencias Sociales, FLACSO Argentina. Autora de La revolución de la píldora. Sexualidad y política en los sesenta (BarceIona: Edhasa, 2012) y coordinadora y autora de Diversidad, sexualidades y creencias. Cuerpo y derecho en el mundo contemporáneo (Toluca/Buenos Aires: Colegio Mexiquense/Prometeo, 2015); Madre no hay una sola. Experiencias de maternidad en la Argentina (Buenos Aires: Ediciones Centro de Integración de Comunicación, Cultura y Sociedad, CICCUS, 2011).

Andrea Rizzotti es Licenciada en Sociología por la Facultad de Ciencias Sociales de la Universidad de Buenos Aires. Actualmente, está terminando sus estudios doctorales en la Facultad Latinoamericana de Ciencias Sociales, FLACSO Argentina, con una investigación sobre aborto no punible en la provincia argentina del Chaco. Es miembro del equipo de investigación Estudios comparados sobre sociedad, cultura e intercultura en América Latina, del Área de Estudios Latinoamericanos de la FLACSO Argentina. Es coordinadora de esta Área, miembro representante en el Consejo Académico de la FLACSO Argentina y directora del Centro de Estudios de CIEE Buenos Aires.

\section{Referencias}

Archetti, E. (1998). Masculinidades múltiples. El mundo del tango y del fútbol en la Argentina. En Daniel Balderston \& Donna J. Guy (comps.). Sexo y sexualidades en América Latina, 291-315. Buenos Aires: Paidós.

Argentina, Ley 26.618, Código Civil. Modificación, Boletín Oficial, 21 de julio de 2010. Recuperado de http://servicios.infoleg.gob.ar/infoleglnternet/anexos/165000-169999/169608/norma.htm

Argentina, Ley 26.873, lactancia materna, promoción y concientización pública, Boletín Oficial, 5 de agosto de 2013. Recuperado de http://servicios.infoleg.gob.ar/infolegInternet/anexos/215000-219999/218212/ norma.htm 
Bailey, J. (1989). Mexico in the U. S. Media, 1979-88. Implications for the Bilateral Relation. En John $\mathrm{H}$. Coatsworth \& Carlos Rico. Images of Mexico in the United States, 55-90. San Diego, California: Bilateral Commission on the Future of United States-Mexican Relations, Center for U. S.-Mexican Studies, University of California.

Breton, D. le (1995). Antropología del cuerpo y modernidad. Buenos Aires: Nueva Visión. Recuperado de https://programaddssrr.files.wordpress. com/2013/05/le-breton-david-antropologia-delcuerpo-y-modernidad.pdf

Burton-Carvajal, J. (1994). 'Surprise package': Looking Southward with Disney. En Eric Smoodin (ed.). Disney Discourse: Producing the Magic Kingdom, 131-147. New York: Routledge.

Butler, J. (2006). Vida precaria. El poder del duelo y la violencia. Buenos Aires: Paidós. Recuperado de http://larevueltabisagra.com.ar/wp-content/ uploads/2013/09/Butler-Judith-Vida-precariaEl-poder-del-duelo-y-la-violencia-2004-ed-Paidos-2006-1.pdf

Diez, M. L. (2004). Reflexiones en torno a la interculturalidad. Cuadernos de Antropología Social, 19, 191-213. Recuperado de http://www.redalyc. org/articulo.oa?id=180913911012

Felitti, K. \& Rizzotti, A. (2013). Cuerpo, género y sexualidad en los programas de intercambio. Experiencias de estudiantes estadounidenses en Buenos Aires. Intersecciones en Comunicación, 7, 41-73. Recuperado de http://www.academia. edu/26001551/Cuerpo_g\%C3\%A9nero_y_sexualidad_en_los_programas_de_intercambio. Experiencias de estudiantes_estadounidenses en_Buenos_Aires

Figueroa, J. G. \& Salguero, A. (2014). ¿Y si hablas de... sde tu ser hombre? Violencia, paternidad, homoerotismo y envejecimiento en la experiencia de algunos varones. Ciudad de México: El Colegio de México.

Fuller, N. (1998). Reflexiones sobre el machismo en América Latina. En Teresa Valdés \& José Olavarría (eds.) (1998). Masculinidades y equidad de género en América Latina, 258-267. Santiago de Chile: Facultad Latinoamericana de Ciencias Sociales, United Nations Fund for Population Activities, FLACSO/UNFPA. Recuperado de http:// www.flacsochile.org/publicaciones/masculiniudades-y-equidad-de-genero-en-america-latina/

Fuller, N. (1995). Acerca de la polaridad marianismo machismo. En Luz Gabriela Arango, Magdalena León \& Mara Viveros-Vigoya (eds.). Género e identidad: ensayos sobre lo femenino y lo masculino, 241-263. Bogotá: Tercer Mundo Editores, Ediciones UniAndes, Programa de Estudios de
Género, Mujer y Desarrollo, Universidad Nacional de Bogotá.

Geertz, C. (1987). La interpretación de las culturas. México: Gedisa.

Giddens, A. (1995). La constitución de la sociedad. Bases para la teoría de la estructuración. Buenos Aires: Amorrortu.

Gutmann, M. C. (1996). The Meanings of Macho. Being a Man in México City. California: University of California Press.

Gutmann, M. C. (1998). El machismo. En Teresa Valdés \& José Olavarría (eds.) (1998). Masculinidades y equidad de género en América Latina, 238-257. Santiago de Chile: Facultad Latinoamericana de Ciencias Sociales, United Nations Fund for Population Activities, FLACSO/UNFPA. Recuperado de http://www.flacsochile.org/publicaciones/ masculiniudades-y-equidad-de-genero-en-america-latina/

Gutmann, M. C. \& Viveros-Vigoya, M. (2007). Masculinidades en América Latina. En Miguel Ángel Aguilar \& Anne Reid (coords.). Tratado de psicología social: perspectivas socioculturales, 120139. Barcelona: Anthropos, Universidad Autónoma Metropolitana, División de Ciencias Sociales y Humanidades.

Lichinizer, D. L. (2014). Del piropo al acoso callejero: relaciones de poder entre mujeres y hombres en el espacio público. Tesis de grado de la carrera de comunicación, Universidad de Buenos Aires (inédita).

Lins-Ribeiro, G. (1989). Descotidianizar. Extrañamiento y conciencia práctica, un ensayo sobre la perspectiva antropológica. Cuadernos de Antropología Social, 2(1), 65-69. Recuperado de http://www.perio.unlp.edu.ar/catedras/system/ files/1.p._lins-ribeiro-descotidianizar-extranamiento-y-conciencia-practica_1.pdf

Locke, John (1689, 1960). Two Treatises of Government. Cambridge, Cambridge University Press.

Petchesky, R. P. (1995). The Body as Property: A Feminist Re-vision. En Faye D. Ginsburg \& Rayna Rapp (eds.). Conceiving the New World Order: The Global Politics of Reproduction, 387-406. Los Ángeles, California: University of California Press.

Ramírez-Berg, C. (2000). Latino Images in Film: Stereotypes, Subversion and Resistance. Austin, Texas: University of Texas Press.

Rodríguez-Rondón, M. A. (2006). ¿Qué es la representación y cuál es su importancia para los estudios sociales? En Mara Viveros-Vigoya, Claudia Rivera \& Manuel Alejandro Rodríguez-Rondón (comps.). De mujeres, hombres y otras ficciones: género y sexualidad en América Latina, 39-45. 
Bogotá: Tercer Mundo Editores, Universidad Nacional, Facultad de Ciencias Humanas. Recuperado de http://www.bdigital.unal.edu. co/1277/3/02CAPI01.pdf, http://www.bdigital. unal.edu.co/1277/

Russell, R. (noviembre/diciembre de 2006). América Latina para Estados Unidos: iespecial, desdeñable, codiciada o perdida? Nueva Sociedad, 206, 48-62. Recuperado de http://nuso.org/articulo/ especial-desdenable-codiciada-o-perdida/

Smith, P. H.; Hausman, B. L \& Labbok, M. H. (eds.) (2012). Beyond Health, Beyond Choice. Breastfeeding Constraints and Realities. New Brunswick, New Jersey: Rutgers University Press.

Stevens, E. (1977). Marianismo: la otra cara del machismo en Latinoamérica. En Ann M. Pescatelo. Hembra y macho en Latinoamérica: ensayos, 121-135. México: Diana.

Stop Street Harassment, SSH (2014). Unsafe and Harassed in Public Spaces: National Street Harassment Report. Reston, Virginia: Stop Street Harassment. Recuperado de http://www. stopstreetharassment.org/our-work/nationalstudy/, http://www.stopstreetharassment.org/ wp-content/uploads/2012/08/National-StreetHarassment-Report-November-29-20151.pdf

Szasz, I. \& Amuchástegui, A. (1996). Un encuentro con la investigación cualitativa en México. En Ivonne Szasz \& Susana Lerner (comps.). Para comprender la subjetividad: investigación cualitativa en salud reproductiva y sexualidad, 17-30. México: El Colegio de México.

Vallejo-Rivera, E. \& Rivarola-Monzón, M. P. (diciembre de 2013). La violencia sexual invisible: acoso sexual callejero en Lima Metropolitana y Callao. Serie Cuadernos de Investigación, 4. Recuperado de http://repositorio.pucp.edu.pe/index/ bitstream/handle/123456789/34946/Cuadernos $\% 20$ de\%20investigaci\%C3\%B3n\%204. pdf? sequence $=1$

Vaquera, E. \& Kao, G. (2005). Private and Public Displays of Affection among Interracial and IntraRacial Adolescent Couples. Social Science Quarterly, 86(2), 484-508.

Viveros-Vigoya, M. (2006). El machismo latinoamericano: un persistente malentendido. En Mara Viveros-Vigoya, Claudia Rivera \& Manuel Alejandro Rodríguez-Rondón (comps.). De mujeres, hombres y otras ficciones: género y sexualidad en América Latina, 111-128. Bogotá: Tercer Mundo Editores, Universidad Nacional, Facultad de
Ciencias Humanas. Recuperado de http://www. bdigital.unal.edu.co/1277/3/02CAPI01.pdf, http://www.bdigital.unal.edu.co/1277/

Wit, H. de; Jaramillo, I. C.; Gacel-Ávila J. \& Knight J. (eds.) (2005). Educación superior en América Latina. La dimensión internacional. Bogotá: Banco Mundial, Mayol Ediciones S.A. Recuperado de http://www-wds.worldbank.org/external/default/WDSContentServer/IW3P/IB/2006/11/10/0 00090341_20061110132821/Rendered/PDF/343 530SPANISH0101OFFICIALOUSE0ONLY1.pdf

Zeitlin, F. I.; Winkler, J. J. \& Halperin, D. M. (1990). Before Sexuality. Princeton: Princeton University Press.

Articulos de prensa

CNN en español (13 de enero de 2014). Papa Francisco: madres pueden amamantar en la iglesia. CNN en español. Recuperado de http://cnnespanol.cnn. com/2014/01/13/el-papa-francisco-les-dice-alas-madres-que-esta-bien-amamantar-en-laiglesia/

La Nación (19 de noviembre de 2014). La pizzería Kentucky pidió perdón por echar a una pareja de lesbianas que se estaba besando. Diario La Nación. Buenos Aires. Recuperado de http://www. lanacion.com.ar/1745292-la-pizzeria-kentuckypidio-perdon-por-echar-a-una-pareja-de-lesbianas-que-se-estaba-besando

Terra (17 de abril de 2014). "Ley Criamor" Por una lactancia sin censura. Terra. Recuperado de https:// vidayestilo.terra.cl/mujer/ley-criamor-por-unalactancia-sin-censura, ac2467eda3175410VgnVC M3000009af154d0RCRD.html

Sitios web

Me quiero ir: http://www.mequieroir.com/paises/ eeuu/emigrar/como-son-los-estadounidenses/

Guía estudiantil internacional: http://www.guiaestudiantilinternacional.com/articles/culture2.htm

Stop Street Harassment: http://www.stopstreetharassment.org/

Stop Telling Women to Smile - Proyecto de arte: http:// stoptellingwomentosmile.com/

Cards against Harassment: http://www.cardsagainstharassment.com/index.html

Real Academia Española: http://dle.rae.es/?id=NnO8B9D

Facebook sobre lactancia: https://www.facebook. com/help/340974655932193/ 